\title{
Research on the Development Process and Optimization Path of Crowdsourcing in China
}

\author{
Yanrong Huang ${ }^{1, \mathrm{a}}$, Bin Huang ${ }^{2, \mathrm{~b}}$, Min $^{\mathrm{Chen}}{ }^{3, \mathrm{c} *}$ \\ ${ }^{1}$ College of Economics \& Management, Zhejiang University of Water Resource and Electric Power, Zhejiang, China \\ ${ }^{2}$ College of Economics \& Management, Zhejiang University of Water Resource and Electric Power, Zhejiang, China \\ ${ }^{3}$ School of Computer Science, Wuhan University, Wuhan, China
}

\begin{abstract}
Crowdsourcing is an important form for enterprises to realize open innovation, which can gather the wisdom of the public and gather talents from various fields to participate in technological innovation and value creation. This paper systematically reviews the emergence and development of crowdsourcing in China, analyzes the causes and characteristics of the four stages of crowdsourcing development with the clue of major events in the development process of crowdsourcing; takes the operation process of crowdsourcing as the breakthrough point, discusses the bidirectional driving optimization path for the benign rolling development of crowdsourcing mode under the background of "mass entrepreneurship and innovation"; and prospects. Finally, the future development direction of crowdsourcing mode is pointed out.
\end{abstract}

\section{Introduction}

With the popularity of the Internet and the rapid development of Web 2.0 technology, a large number of individuals connect with each other through the Internet, and participate in online value creation part-time or fulltime, giving birth to a new open innovation form crowdsourcing. In 2006, Howe, a reporter from wired magazine of the United States, proposed the concept of crowdsourcing. He pointed out that the practice of a company or organization to outsource the work tasks performed by employees freely and voluntarily to a nonspecific (usually large) mass network is called crowdsourcing [1]. According to the relationship between participants, Afuaha et al. divided them into cooperative and competitive types Collaborative crowdsourcing [2], such as open source model and Wiki model, is used to solve problems. Competitive crowdsourcing is defined as competitive crowdsourcing that accepts individual or organizational tasks to win in competition. In China, competitive crowdsourcing is also known as Witkey [3].

Crowdsourcing mobilizes idle labor resources on the network and has the advantages of high efficiency and low cost for solving knowledge-based problems [4]. Some domestic and foreign enterprises realize open innovation through crowdsourcing. For example, Procter \& Gamble integrates the wisdom of tens of thousands of technical experts around the world and seeks solutions to problems through Innovative platform, the R \& D capability of the company is increased by $60 \%$, the proportion of external innovation is increased by $35 \%$, and the $\mathrm{R} \& \mathrm{D}$ cost is reduced by $20 \%$. Huawei released icon and desktop wallpaper design tasks through crowdsourcing platform, and obtained more than 2000 creative works. Crowdsourcing connects crowdsourcing participants with task publishers through crowdsourcing platform, breaking the limitations of time, space and region. Task publishers release tasks through crowdsourcing platform, and use the wisdom of crowdsourcing participants to solve problems. Crowdsourcing participants are paid to participate online and complete tasks. Crowdsourcing promotes the idle labor force on the network to participate in innovation and value creation, changes the traditional organizational production mode, forms a new production factor and labor mode [5], achieves the multiplier effect of pooling wisdom and strength, improves the innovation efficiency [6], shortens the innovation path, realizes the effective integration of social resources, and improves the social operation efficiency.

After more than ten years of development, crowdsourcing research has accumulated a lot of academic achievements, and its research focuses on the research of participants, including task publisher, crowdsourcing platform and crowdsourcing participants. The application fields of crowdsourcing mainly involve business field, computer field, logistics field, library information field, scientific research field and education. At present, some scholars have summarized the relevant research on crowdsourcing mode from different angles. For example, Zhang Libin et al. [7] from the perspective of management, summarized the motivation of crowdsourcing participants to participate in tasks and the impact on enterprise performance, and put forward

ahuangyr@zjweu.edu.cn, bhuangbin@zjweu.edu.cn, ${ }^{* c}$ Corresponding author: chenmin@whu.edu.cn 
development suggestions of using the Internet, selecting the appropriate public, and standardizing the system. From the perspective of computer science, Feng Jianhong et al. [8] summarized the existing technology research results from three aspects of task preparation, implementation and answer. Dong Kunxiang et al. [9] from the perspective of statistics, takes the database as the sample, and statistically analyzes the citation network, main path and keywords of crowdsourcing mode research through Citation visualization software. Xia Enjun et al. [10] from the perspective of open innovation, analyzed the driving factors of crowdsourcing participants' participation, and summarized the influencing factors of innovation performance. Yan Jie et al. [11] from the perspective of the participants of crowdsourcing, summarized the research related to the participants, and constructed the general framework of crowdsourcing workflow et al.

However, there has been litter discussion about the crowdsourcing development path and direction with Chinese characteristics under the background of mass entrepreneurship and innovation. To date, no research has been done on development process of crowdsourcing, development path and direction of crowdsourcing. The practice of crowdsourcing creates new economic and social values, and also brings new research topics. To systematically combs the development track of crowdsourcing, and discuss development path of crowdsourcing, it is of great significance to promote the practical application and theory of crowdsourcing, fully release the innovation and entrepreneurship potential of the whole society, accelerate the transformation of scientific and technological achievements, realize innovation driven development, expand employment, and promote the adjustment of China's economic structure.

\section{Development Process of Crowdsourcing in China}

According to the systematic literature review, referring to the views of relevant scholars, combined with the major events in the development process of crowdsourcing, this paper divides the development process of crowdsourcing in China into four stages: formation stage (2000-2005), outbreak stage (2006-2007), downturn stage (2008-2010) and growth stage (2011-present). The analysis of the causes and characteristics of each stage is shown in the table I.

\subsection{Formation stage (2000-2005)}

At the beginning of this century, with the popularity of the Internet, the earliest crowdsourcing platform appeared in China, opening a new field of Internet payment to solve problems. In 2000, Shenzhen's "Designer's Window" and other platforms began to provide services to worldfamous enterprises in the form of task bidding; in 2003, the "K68 creative industry platform" was established. In 2005, Liu Feng called the person who converted his wisdom, knowledge, ability and experience into actual income through the Internet as "Witkey", and the activity of transforms intellectual achievements into actual benefits called "Witkey Mode".

\subsection{Outbreak stage (2006-2007)}

In 2006, the crowdsourcing attracted media attention. The 21 st century economic daily took the lead in reporting, and then more than a dozen media including CCTV followed up and reported the crowdsourcing. The number of visits to the crowdsourcing platform has increased dramatically. The number of tasks of Zhubajie platform has soared from nearly 100 to 228 . In two days, the number of independent users of the website has increased from more than 1000 independent IP addresses to tens of thousands, and the number of hits has exceeded 100000 . Since then, dozens of media at home and abroad, such as South Korea, Russia, Germany and the United Kingdom, have also reported on the crowdsourcing.

\subsection{Downturn stage (2008-2010)}

The outbreak of crowdsourcing is like discovering a new Internet continent, but its operation is very difficult. In the face of various tasks covering science and technology, learning, work and life, the single cash reward task lacks universality, and the bidding task form appears; the market segmentation of crowdsourcing mode appears, and some platforms focus on serving a certain field or industry, such as translation, program development. The market competition pattern has initially formed, and Zhubajie platform has become the industry leader.

\subsection{Growth stage (2011 to present)}

In recent years, with the promotion of market and government, crowdsourcing platform has developed rapidly. Since 2011, crowdsourcing platform has changed profit model, improved trading mechanism, opened up financing channels, and developed rapidly with the support of government policies. In 2015, the State Council put forward suggestions on policies and measures for mass entrepreneurship and innovation; in 2016, China's 13th five year plan clearly proposed the implementation of innovation driven development strategy; in 2017, the State Council discussed and passed the opinions on strengthening the implementation of innovation driven development strategy. Crowdsourcing is an important form of innovation driven development in China. Crowdsourcing platform has also become a supporting platform for "Mass Entrepreneurship and Innovation" in China. 


\section{Optimization Development Path of Crowdsourcing in China}

\subsection{Development path of crowdsourcing under background of mass entrepreneurship and innovation}

Under the background of mass entrepreneurship and mass innovation, crowdsourcing develops from open innovation to innovation and entrepreneurship combination. Crowdsourcing platform from providing transaction support to providing financial support, service support and scenario support, the service is increasingly perfect. In terms of financial support,service is increasingly perfect. In terms of financial support, it provides financial services such as micro loans, funds, Internet insurance, financial management and asset management. For example, Bajie finance has provided financial services to more than 100000 small and micro loan users, with financial assets of more than 5 billion yuan. In terms of service support, it provided industrial and commercial registration, tax registration and banking registration services,

TABle I. Development Process of Crowdsourcing in China

\begin{tabular}{|c|c|c|}
\hline $\begin{array}{l}\text { Devel } \\
\text { opme } \\
\text { nt } \\
\text { stage }\end{array}$ & $\begin{array}{l}\text { Time } \\
\text { phase }\end{array}$ & Development events \\
\hline $\begin{array}{l}\text { Form } \\
\text { ation } \\
\text { stage }\end{array}$ & $\begin{array}{l}2000- \\
2005\end{array}$ & $\begin{array}{l}\text { - In 2004, Shenzhen "designer's window" to explore the } \\
\text { form of bidding task. } \\
\text { - In April 2004, K68 creative platform released No. } 1 \\
\text { task. } \\
\text { - In July 2005, Liu Feng proposed "Witkey" for the first } \\
\text { time. } \\
\text {-At the end of 2005, "Witkey", "Zhubajie "and other } \\
\text { platforms were established one after another } \\
\text {-In July 2006, CCID released the Research Report of } \\
\text { Witkey business model and investment prospect in } \\
\text { China. } \\
\text {-In 2006, Howe, proposed crowdsourcing, and } \\
\text { introduced "Innocentive", "iStockphoto" and other } \\
\text { crowdsourcing platforms. }\end{array}$ \\
\hline
\end{tabular}

Cause

Development
characteristics

\begin{tabular}{ll}
\hline Outbr & $2006-$ \\
eak & 2007 \\
stage &
\end{tabular}

\begin{abstract}
-In September 2006, more than ten media reported crowdsourcing one after another, causing concern by crowd;

-In September 2006, the reward task of 300000 bonus appeared on Zhubajie platform;

-In January 2007, Witkey was selected as the annual Chinese Neologism of the Ministry of education;

-In June 2007, Witkey was selected for the college entrance examination.
\end{abstract}

- Internet

popularization and technological progress are the basic conditions; - Open innovation is the internal motivation; Knowledge value is the catalyst.

is

.

\section{-The emergence of} crowdsourcing comes from the enterprise demand of open innovation; - The practice of crowdsourcing promotes the theoretical research of crowdsourcing. round 2005, domestic and foreign scholars have successively launched theoretical research on crowdsourcing.

-Emerging new -The extensive
trading areas, and attention of the market prospects are media has aroused

\begin{tabular}{|c|c|c|}
\hline $\begin{array}{l}\text { Down } \\
\text { turn } \\
\text { stage }\end{array}$ & $\begin{array}{l}2008- \\
2010\end{array}$ & $\begin{array}{l}\text {-In } 2008 \text {, Zhubajie platform became one of China's top } \\
100 \text { commercial websites and won the title of the most } \\
\text { valuable website of the year. In } 2009 \text {, its total number of } \\
\text { tasks increased from } 587 \text { to more than } 50000 \text {, accounting } \\
\text { for half of the industry and becoming the industry leader. } \\
\text {-In November } 2010 \text {, the first Witkey conference was } \\
\text { held in Chongqing, China. }\end{array}$ \\
\hline
\end{tabular}
-At the end of 2010, there were more than 100 crowdsourcing platforms, some of which were large and complete, and a few stood out. The number of registered members exceeded 20 million and the cumulative transaction volume exceeded 300 million yuan. broad.

-The development of crowdsourcing is restricted by problems of user acceptance and transaction echanism. social concern; $\cdot$ High IP traffic does not bring explosive growth of transaction volume.

-The Internet credit $\begin{aligned} & \text { The number of } \\ & \text { system is not crowdsourcing }\end{aligned}$
perfect, and both platforms has sides of the increased rapidly, transaction are lack and it has developed of transaction trust. into specialized -The form of fields, such as transaction is single, translation and and lacks program universality; development

-Transaction system -The number of reduces transaction registered people and expectation of task transaction amount publisher. increased slowly of crowdsourcing, and the market competition pattern initially formed. 


\begin{tabular}{|c|c|c|}
\hline $\begin{array}{l}\text { Grow } \\
\text { th } \\
\text { stage }\end{array}$ & $\begin{array}{l}\text { Since } \\
2011\end{array}$ & $\begin{array}{l}\text {-In 2011,Yipinweike platform created the first free } \\
\text { Commission regulations. } \\
\text {-In } 2012 \text {, the direct employment mode was launched; } \\
\text {-At the end of } 2014 \text {, Zhubajie crowdsourcing platform } \\
\text { was free of commission and provided value-added } \\
\text { services, ushering in a sharp increase in transaction } \\
\text { volume; } \\
\text {-In } 2015 \text {, Zhubajie platform obtained a huge amount of } \\
\text { financing of } 2.6 \text { billion yuan } \\
\text {-In October } 2015 \text {, Yipin Witkey maker space was } \\
\text { awarded the "cross strait youth entrepreneurship base" } \\
\text { by the Taiwan Affairs Office of the State Council; } \\
\text {-In December } 2016 \text {, the number of registered users of } \\
\text { Crowdsourcing platform exceeded } 16 \text { million, and the } \\
\text { annual transaction volume exceeded } 100 \text { million yuan in } \\
2010 \text { and reached } 31 \text { billion yuan in } 2016 \text {; } \\
\text {-In June } 2017 \text {, Zhubajie platform was selected into the } \\
\text { second batch of national innovation and } \\
\text { entrepreneurship demonstration bases; } \\
\text {-Since } 2018 \text {, a number of crowdsourcing platforms was } \\
\text { recognized by national maker space, selected as the } \\
\text { sharing economy demonstration platform of the national } \\
\text { development and Reform Commission, the fourth batch } \\
\text { of national entrepreneurship incubation demonstration } \\
\text { bases et al.. }\end{array}$ \\
\hline
\end{tabular}

\begin{tabular}{|c|c|}
\hline $\begin{array}{l}\text { Further strengthen } \\
\text { he construction of } \\
\text { ts own platform, } \\
\text { gradually improve } \\
\text { he trading } \\
\text { mechanism, free of } \\
\text { commission, remote } \\
\text { communication and } \\
\text { ther technical } \\
\text { problems have been } \\
\text { solved, forming } \\
\text { hree types of tasks: } \\
\text { full reward, bidding } \\
\text { ask and direct } \\
\text { employment; } \\
\text { The government's } \\
\text { support for } \\
\text { crowdsourcing has } \\
\text { ncreased, the } \\
\text { crowdsourcing } \\
\text { platform has } \\
\text { oecome a supporting } \\
\text { platform for } \\
\text { entrepreneurship }\end{array}$ & $\begin{array}{l}\text { Crowdsourcing } \\
\text { platforms have } \\
\text { changed their profit } \\
\text { models, reduced the } \\
\text { threshold for traders } \\
\text { to participate, and } \\
\text { the trading volume } \\
\text { increased sharply. } \\
\text {-Some } \\
\text { crowdsourcing } \\
\text { platforms are } \\
\text { supported by multi- } \\
\text { party financing, } \\
\text { including private } \\
\text { capital, state-owned } \\
\text { enterprises and } \\
\text { government funds. } \\
\text {-The trading } \\
\text { mechanism of } \\
\text { crowdsourcing mode } \\
\text { is becoming more } \\
\text { and more perfect, } \\
\text { and mobile clients } \\
\text { are getting more and } \\
\text { more attention. } \\
\text { ·With the support of } \\
\text { government policies, } \\
\text { crowdsourcing mode } \\
\text { has developed } \\
\text { rapidly, and from } \\
\text { "non physical goods" } \\
\text { trading to the } \\
\text { direction of a } \\
\text { combining a } \\
\text { innovation and } \\
\text { entrepreneurship. }\end{array}$ \\
\hline
\end{tabular}
the construction of platforms have its own platform, changed their profit gradually improve models, reduced the the trading threshold for traders to participate, and communication and increased sharply. other technical -Some problems have been crowdsourcing forming platforms are full reward, bidding party financing, task and direct including private employment; -The government's enterprises and support for government funds. increased, the mechanism of crowdsourcing crowdsourcing mode and mobile clients entrepreneurship are getting more and more attention. government policies crowdsourcing mode has developed from rading to the combining entrepreneurship. intellectual property agency, education and training, printing, website construction, brand building, marketing planning, product promotion and other one-stop service support. In the aspect of scene support, crowdsourcing platform has carried out in-depth cooperation with local governments,carried out construction projects of physical entrepreneurship parks with provinces, cities, autonomous regions and municipalities directly under the central government, provided offline fixed office space, realized the docking of online trading platform and offline entity entrepreneurship park, opened up online and offline channels, and provided full life cycle services for the crowdsourcing entrepreneurs. At present, the Zhubajie park has been settled in Kunming, Changsha, Tianjin, Chengdu, Beijing and Urumqi, and has become an integrated demonstration base for local Internet plus entrepreneurship and innovation. The Beijing venture's Pioneer Park is planned to build a national innovation and entrepreneurship demonstration park in 2020.

Under the background of mass entrepreneurship and innovation, crowdsourcing platform has become a supporting platform for a large number of veterans, unemployed people, migrant workers, college graduates, scientific and technological personnel with dreams, willingness and ability to participate in innovation and value creation, and realize independent entrepreneurship. Crowdsourcing participants through platform participate in valute innovation and creat to realize independent entrepreneurship, opening studios, small companies and even medium-sized companies, it can solve the problem directly and indirectly social employment. 


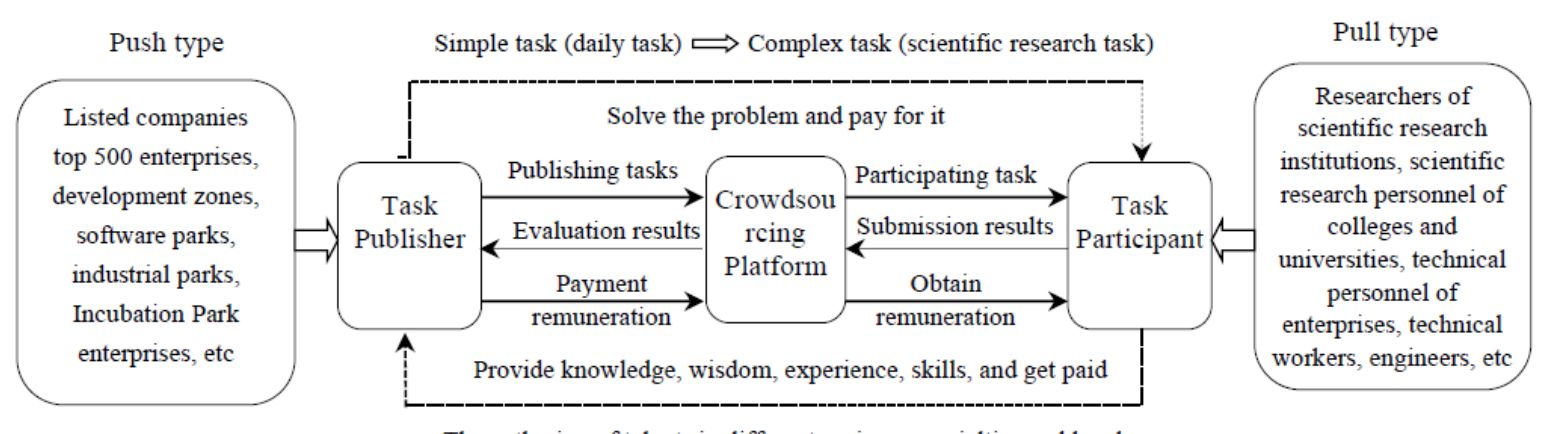

The gathering of talents in different regions, specialties and levels

FIGURE 1. Optimization development path of crowdsourcing

\subsection{Optimal development path of crowdsourcing mode driven by bidirection}

In order to realize the benign rolling operation of crowdsourcing in the future, it is necessary to pull the continuous rolling participation of task publishers and middle and high-end crowdsourcing participants, so as to realize the bidirectional driving development path of "push" and "pull". Crowdsourcing is to release task information through crowdsourcing platform, gather labor resources, and provide knowledge, wisdom, experience and skills for crowdsourcing participants to complete tasks and realize open innovation. The specific operation process of crowdsourcing mode is as follows: the task publisher releases the required tasks, while trusting the funds, crowdsourcing participants (platform registered members) $\log$ in to the website to take the task actively, submit the results as required, and the task publisher pays to crowdsourcing participants after receiving the task results, as shown in Figure 1.

The development of crowdsourcing mode needs to combine "push type" and "pull type" mode. On the one hand, with the support of government policies, "push" more task publishers to participate in crowdsourcing. Under the support of the public entrepreneurship and innovation policy, the government creates a good innovation environment. Through the government's guidance, a large number of task publishers are invited to join, and Chinese listed companies, top 500 enterprises, development zones, software parks, industrial parks and incubator park enterprises are promoted to enter the crowdsourcing platform. Enterprises are encouraged to seek solutions to the problems they cannot solve through the crowdsourcing platform and release the real ones. On the other hand, the crowdsourcing platforms "pull" more and more middle and high-end crowdsourcing participants to participate in the task, and promotes the rolling participation of researchers, University researchers, enterprise technicians, technical workers, engineers and other talents at all levels, and establish talent think tanks to form a strong talent aggregation effect. Under the support of national policies and market mechanism, crowdsourcing mode achieves the aggregation from simple tasks to complex tasks, and from daily life tasks to scientific research tasks. As innovation becomes more and more complex, it needs to combine various knowledge sources and span multiple fields. Crowdsourcing participants from different fields and countries are widely involved to realize the aggregation of talents from different regions, specialties and levels, and then produce a strong aggregation effect. The crowdsourcing mode realizes the benign rolling development driven by twoway.

At present, the crowdsourcing in China needs to solve the following problems in order to realize the two-way driving development path of "push" and "pull".

3.2.1 Improve the trading system of crowdsourcing platform. At present, the tasks of crowdsourcing platform mainly focus on logo design, website construction, network promotion and brand planning. To obtain the statistical data of Zhubajie platform of January, 2019, it is found that turnover volume of Zhubajie platform is 534178 , the total transaction volume is 560370000 yuan, and the average transaction price of the task is 1049 yuan. Perfecting the trading system is the basic condition for the crowdsourcing to realize the benign rolling development. The crowdsourcing platform should gradually improve the trading mechanism by realizing intelligent matching of tasks under multi-dimensional constraints, establishing a promotion system for task price evaluation, building a multi-dimensional reputation evaluation system for traders, and achieving task quality control. The perfect trading mechanism of crowdsourcing platform can effectively avoid adverse selection, reduce transaction costs, prevent transaction risks, ensure the quality of task completion, and ensure the healthy operation of crowdsourcing mode.

\subsubsection{Encourage more organizations and} individuals to participate in crowdsourcing activities. The benign rolling development of crowdsourcing depends on the continuous and stable participation of task publishers and crowdsourcing participants. How to stimulate the enthusiasm of participants is an urgent problem to be solved. At present, most of the academic achievements focus on the behavior, intention and motivation of crowdsourcing participants, while there is little research on task publishers. There is no study on the influence of organizational ability, culture, expectation, risk identification and other factors on the participation behavior of task publishers. According to the law of sturgeon, $1 \%$ of users are creators, $10 \%$ of users are participants, and $90 \%$ of users are silent. How to stimulate the participation of middle and high-end crowdsourcing participants, gather the people who have the ability to solve problems, establish a crowdsourcing participant team, and 
solve complex tasks, are the difficulties faced by the development of crowdsourcing.

3.2.3 Increase government support. In the 2015, Premier Li Keqiang proposed that "relying on the Internet plus" and other new technologies and modes to build the most extensive platform for innovation, encourage the development of public innovation, crowdsourcing, public support and crowd financing, so that the allocation of innovative resources will be more flexible and precise, and the wisdom of the masses can be gathered, forming an innovative pattern of the integration of the internal brain and the external brain, and the collaboration between enterprises and individuals.Subsequently, the State Council issued the guiding opinions on accelerating the construction of a support platform for mass entrepreneurship and innovation, which proposed to "actively promote crowdsourcing and stimulate the vitality of entrepreneurship and innovation." In 2016, Guangdong Province took the lead in carrying out the pilot work of scientific research crowdsourcing platform, providing financial support to the operating agencies included in the pilot platform. The local government has issued effective measures and measures from the aspects of technology, capital and talents to create a good development environment, which will enhance the role of the crowdsourcing in the transformation and upgrading of enterprises, industrial innovation, mass entrepreneurship and mass innovation.

3.2.4 Introduce social financial capital. Under the background of mass entrepreneurship and innovation, it will be the future development trend of crowdsourcing mode to realize the financing of creative projects or intellectual achievements formed by personal wisdom, knowledge, ability and experience through crowdsourcing platform. Task publishers release financing tasks of creative projects or intellectual achievements through crowdsourcing platform. Crowdsourcing platform introduces social financial capital, evaluates creative projects or intellectual achievements, and injects capital to incubate creative projects or intellectual achievements, so as to realize seamless docking of innovation and entrepreneurship. The government should give full play to the guiding role of policies and special financial funds, drive social financial capital to join, and establish a collaborative mechanism of "government guidance and market leading"; relying on the government's credibility, enhancing the trust and participation of task publishers, financial investment institutions and crowdsourcing participants will effectively promote the coordinated development of innovation and entrepreneurship.

\section{Summary and Prospect}

Crowdsourcing is a new open innovation form in which users participate in value creation. After more than ten years of development in China, crowdsourcing has roughly gone through four stages: formation stage, outbreak stage, downturn stage and growth stage, and has formed the development mode with Chinese localization characteristics. Under the background of mass entrepreneurship and innovation, crowdsourcing is developing towards the combination of innovation and entrepreneurship, online and offline. In order to realize the benign rolling operation of crowdsourcing in the future, it is necessary to promote the continuous rolling participation of task publishers and middle and high-end crowdsourcing participants, and realize the two-way driving development path of "push" and "pull". The specific measures include: further improve the trading system of crowdsourcing platform, stimulate more organizations and individuals to participate in crowdsourcing activities, increase government support, and introduce social and financial capital. It can be predicted that as more and more individual participants with different knowledge, experience and skills come to crowdsourcing activities, more and more enterprises adopt crowdsourcing mode and seek external innovation mode of absorbing external resources and utilizing knowledge. In the future, "super crowdsourcing platform" will appear in China. "Super crowdsourcing platform" will optimize the allocation of labor resources through industry segmentation and high-efficiency cooperation, and realize the network collaborative value creation and innovation, resulting in a large cycle of talent gathering, value creation and innovation.

\section{Acknowledgment}

This work was supported by the Scientific Research Projects of Zhejiang Education Department under Grant Y202045307.

\section{References}

1. J. Howe, "Crowdsourcing: Why the Power of the Crowd Is Driving the Future of Business," American Journal of Health-System Pharmacy, vol.67, pp.1565-1566, 2010.

2. T.Afuaha, "Crowdsourcing as a Solution to Distant Search," Academy of Management Review, vol.37, pp.355-375, 2012.

3. M. Tao, Y. Zhang, D. H. Dong, "Research on Influencing Factors of Crowdsourcing Participation Behavior Based on Witkey mode." China Soft Science, vol. 12, pp.112-123, 2014.

4. DC. Brbham, "Crowdsourcing" Cambridge, The MIT Press, 2015.

5. M. Mount, H. Round, T. S. Pitsis, "Design Thinking Inspired Crowdsourcing: Toward a Generative Model of Complex Problem Solving," California Management Review, vol 62, pp.1-12, 2020.

6. M. Boons, D. Stam, "Crowdsourcing for innovation: How related and unrelated perspectives interact to increase creative performance," Research Policy, vol.48, pp.1758-1770, 2019. 
7. L. B. Zhang, F. P. Zhong, H. Tu, "A Survey of Crowdsourcing Problem," Science\&Technology Progress and Policy, vol. 29, pp. 154-160, 2012.

8. J. H. Feng, G. L. Li, J. H. Feng, "Review of Crowdsourcing Technology,"Chinese Journal of Computers, vol. 38, pp.1713-1726, 2015.

9. K. X. Dong, W. H. Hou, Z. X. Xie, et al., "Evolution Path and Future Prospect of Crowdsourcing Research at Home and Abroad," Science\&Technology Progress and Policy, vol. 33, pp. 154-160, 2016.

10. E. J. Xia, X. W. Zhao, S. Li, "Research Status and Trend of Crowdsourcing Abroad," Journal of Technology Economics, vol. 34, pp.28-36, 2015.

11. J. Yan, R. J. Liu, H. Liu, "Review of Crowdsourcing Research at Home and Abroad," Forum on Science and Technology in China, vol.8, pp. 59-68+151, 2017. 